\title{
Evidence Of Social Desirability Response Bias In Ethics Research: An International Study
}

Richard A. Bernardi, (E-mail: rbernardi@rwu.edu), Roger Williams University Erin L. Delorey, Roger Williams University

Catherine C. LaCross, Roger Williams University

Rebecca A. Waite, Roger Williams University

\begin{abstract}
This paper analyzes the association between ethical perceptions of questionable business practices and Hofstede's Individualism, Transparency International's Corruption Index, and social desirability response bias. The sample consists of 1,048 business students from ten countries: Canada, Colombia, Ecuador, Hong Kong, Ireland, Japan, Nepal, South Africa, Spain, and the United States. The results of our analysis indicate that, while Hofstede's (1980) cultural construct of Individualism was significant for two of the questions, social desirability response bias was the most consistent variable in modeling subjects' responses. Our data indicate that social desirability response bias should be controlled for when using self-reported data in ethics and/or international studies.
\end{abstract}

\subsection{Introduction}

1

$\mathrm{n}$ light of the Enron disaster and other corporate failures, unethical business practices are a significant concern of corporate stakeholders as well as the general public. In order to study unethical business practices, research has examined the decision processes of business students, corporate employees and managers. Many studies have limited samples such as participants from only the United States. However, the business world is quickly becoming a borderless global community and Enderle $(1997,1477)$ believes that:

If business ethics is a relatively new field, then international business ethics is brand new, and needs a great deal of attention in order to better understand not only the international challenges but also the domestic ones, since both are increasingly interconnected.

Problems arising from the lack of business ethics are evident in all regions of the world. Many believe that, when people fail to consider moral implications and only consider the bottom line, unethical practices such as bribes, tax evasion, and black marketeering flourish (Chakraborty 1997). For example, in Latin America, family values do not carry forward into the work environment (Arruda 1997). Similarly, business ethics do not associate with family and governmental values in Japan (Taka 1997). Latin Americans believe that one who "does not act unethically does not succeed" (Arruda 1997, 1598). Additionally, Taka reports that Japan has lagged behind American and European counterparts (Dunfee and Werhane 1997) in areas such as outside directors, hot-lines, and codes of ethics.

Compounding these factors is the relative immunity to legal sanctions of white-collar crimes in many countries. In South Africa, "white collar crime has more than doubled during the first year of the newly formed democratic government" (Rossouw 1997, 1540). In developing countries, the uncertainty of social/governmental structures and language also inhibit business ethics. The lack of structure and morality necessary to respond to the

Readers with comments or questions are encouraged to contact the authors via email. 
demands of expanding technologies inhibit ethical practices in India (Chakraborty 1997). While most of Latin America shares a common language, this is not the case in other regions such as Europe (van Luijk 1997). Given the worldwide nature of unethical business practices, Rossouw (1997) suggests that ethics research needs to be more global.

Duizend and McCann (1998) conducted a study of college business students and their attitudes toward possible unethical corporate situations; however, their study was limited to the students in the United States. Our study builds on their research and goes one step further by investigating the attitudes of business students from five geographic areas and ten countries including two from North America (Canada and the United States), two from South America (Colombia and Ecuador), two from Europe (Ireland and Spain), and three from Asia (Hong Kong, Japan, and Nepal) and one from Africa (South Africa). We used college students because they are the next generation of business managers and because they have been deluged with examples of unethical business practices in the press. Consequently, we believe that studying the attitudes of a group of international business students may provide an insight into what the future may hold for business ethics.

\subsection{Theory Development}

\subsection{Corruption and Culture in Ethics Research}

In one sense, bribery can be defined as "the propensity of companies from leading exporting countries to pay bribes to senior public officials" (Transparency International 2002, 2); this definition is used as the basis for Transparency International's Bribe Payers Index. In the United States, federal-sentencing guidelines serve to deter potential corporate bribery and stimulate ethics programs (Dunfee and Werhane 1997). However, Enderle (1996) notes that, while regulations in the United States are concerned with relatively micro-issues (i.e., a rules-based approach), European legislation focuses on macro-issues (i.e., a concepts-based approach).

Although corruption can be reduced by decreasing (increasing) it's expected profits (the probability of its detection), "there is a need for a clearer ethical stance" (Argandona 1999, 164). For example, bribery is a central issue in many of the recent scandals in Japan and is "deeply rooted in the Japanese way of doing business" (Taka 1997, 1502). Enderle (1997) suggests that one of the challenges for South Africa, Latin America, and India is the elimination of corruption. For instance, Rossouw (1997) indicates that only ten percent of white-collar crimes are reported in South Africa; of these, only about half are prosecuted. Latin American countries have problems with business ethics because corruption is common in the upper levels of government/corporations and low economic development has affected the workplace (Arruda 1997). While "scams" are common in India, corruption is an expensive problem to completely eliminate for both monetary and social reasons (Enderle).

While an ideal measure of the propensity for bribery in a country is Transparency International's Bribery Index, this index currently includes only 21 countries. ${ }^{1}$ However, the correlation between Transparency International's Corruption Perceptions Index (2002) and their Bribery Index is .75 (adjusted $\mathrm{r}^{2}$ of .56). Consequently, we used Corruption Perceptions Index (2002) as a surrogate for the Bribery Index.

H1: Participants from more corrupt countries will perceive the action proposed in the scenario as being more ethical.

Hofstede (1991, p.112) defines culture as a system of shared values and beliefs that represent a "set of likely reactions of citizens with a common mental programming. [These] reactions need not be found within the same persons, but only statistically more often in the same society." Hofstede identified Individualism, Power Distance, Uncertainty Avoidance, and Masculinity/Femininity as the four constructs of a country's culture. Hofstede (1984, p. 83) describes Individualism as:

Individualism stands for a preference for a loosely knit social framework in society wherein individuals are supposed to take care of themselves and their immediate families only. The fundamental issue addressed by this dimension is the degree of interdependence a society maintains among individuals. 
Triandis (1984) and Triandis et al. (1988) believe that Hofstede's Individualism construct inherently reflects the spectrum of beliefs between focusing on the individual's interests to a concern for the entire society in more collectivist societies. For example, Hofstede maintains that the individualism construct implies that, in more individualistic cultures "everyone is supposed to take care of him or herself and his or her immediate family; "I" consciousness; and Self-orientation" (1984, p. 235). Karnes et al. (1989) suggest that culture could cause differences in interpretations of ethical issues.

Kohlberg's (1969) model is one way of explaining the thought process used by an individual to reason in ethical situations. Rest (1979a) developed a test to measure moral developing using Kohlberg's model and stages. Rest's Defining Issues Test (1979b) uses Stages Two through Six of Kohlberg's model (i.e., the lowest stage is not examined in the Defining Issues Test). If one views Stages Two-through-Six as a spectrum of reasoning, it can be related to Hofstede's (1984) construct of Individualism. Stage Two is Rest's equivalent to Hofstede's highly individualistic society where personal interests dictate behavior. The criterion for decision making in Stage Two relates to the costs and benefits to the individual. Relationships with others in one's social environment provide the moral perspective in Stage Three. In this stage, cooperative behavior within the group is the standard for individuals; costs and benefits to the group now determine behavior. Stage Four individuals are very rule oriented; these rules are those of a vastly larger society and not just those of one's immediate environment. In Stage Four, individuals ensure the proper functioning of their society by following its rules. Stage Five's conception of norms includes protecting and maximizing the rights and welfare of all individuals. In this stage, individuals determine the rules that should be followed by evaluating the fairness of the process used to develop the rules. Finally, Stage Six individuals separate conventions and laws of the society from more general principles; individuals follow the society's rules that are rational and impartial.

Wingate (1997) found that, as Hofstede's (1980) cultural construct of Individualism increased, litigation related to business in the country also increased. Arnold et al. (1999) offer an explanation for this finding. They used a scenario involving an auditor who had a history of being over his time budget. In the scenario, the auditor could either do more audit work or sign-off on an incomplete audit. While doing more audit work would result in being over budget and jeopardize his job, signing off on an incomplete audit would allow him to meet his time budget. Arnold et al. (1999) found that, as Hofstede's Individualism construct increased, the probability of doing more audit work decreased. Consequently, we believe that:

H2: Participants from more Individualistic countries will perceive the action proposed in the scenario as being more ethical.

\subsection{Gender and Social Desirability Response Bias in Ethics Research}

Bernardi and Arnold (1997) found that women scored higher than men on the DIT, which suggests that women are more sensitive to ethical issues and to the conclusion that a "significantly higher percentage of women than men believe that the illegal or dishonest behavior is never justifiable" (Swamy et al. 2001, 28). Beltramini et al. (1984) maintain that ethical issues are a greater concern to female students; in the replication study, Peterson et al. (1991) report similar results. Peterson et al. found that, even though the actual differences were not large, they were significant for eight out of ten issues examined. Interviews conducted and reported by Adams et al. (1999) showed that, while female business students showed an improvement over time, the ethical choices of male business students declined. As a result of these studies, there should be a significant difference between the responses of male and female students:

H3: Female participants will perceive the action proposed in the scenario as being less ethical than male participants will.

Robertson and Anderson (1993) maintain that, if individuals can project themselves into a situation, they may respond to questions in a socially desirable manner. Social desirability response bias was a significant factor in individuals' self-reported tendency to modify their private beliefs based on their peer-group's values (Cote and Sanders, 1997). There are two aspects to social desirability response bias. The first occurs when individuals over- 
report activities deemed to be socially/culturally desirable; the second occurs when activities are under-reported because they are socially/culturally undesirable (Ganster et al. 1983; Zerbe and Paulhus 1987). For example, Gendall et al. (1982) believe that undesirable acts such as smoking are underreported, while actions such as donations to charities are likely to be over-reported. Additionally, research indicates that a significant percentage of the convicted drunken drivers are unwilling to report their conviction (i.e., undesirable behavior) when questioned about their driving records (Kalton and Schuman 1982).

H4: Participants who score higher (lower) on a measure of social desirability response bias will perceive the action proposed in the scenario as being less (more) ethical.

\subsection{Subjects and Measures}

\subsection{Sample}

Our initial sample included the responses of 1,433 students from ten countries. ${ }^{2}$ Because the focus of our research is the ethical perceptions of business majors, we only considered the responses of the 1,048 business majors. We did not use the samples of male students from Nepal and female students from Japan in our analysis because of their size. Consequently, our final sample size was 1,037 $(1048-(4+7))$. Our sample (Table 1) represents six of Wingate's $(1997,143)$ nine cultural areas in the world: More Developed Latin (Spain), Less Developed Latin (Colombia and Ecuador), More Developed Asian (Japan), Less Developed Asian (Nepal), Asian Colonial (Hong Kong), and Anglo (Canada, Ireland, United States, and South Africa). ${ }^{3}$

TABLE 1: Sample Sizes by Country and Gender

\begin{tabular}{lccc}
\hline Country & Men & Women & Total \\
\hline Canada & 30 & 44 & 74 \\
Colombia & 51 & 126 & 177 \\
Ecuador & 19 & 51 & 70 \\
Hong Kong & 35 & 55 & 90 \\
Ireland & 69 & 42 & 111 \\
Japan & 44 & 7 & 51 \\
Nepal & 4 & 19 & 23 \\
South Africa & 76 & 55 & 131 \\
Spain & 45 & 36 & 81 \\
United States & 134 & 106 & 240 \\
Total & 507 & 541 & 1,048 \\
& \multicolumn{3}{|}{} \\
Shaded Areas & These samples were not used in the analysis. \\
& \multicolumn{3}{l}{}
\end{tabular}
includes a crosscheck of two groups with similar scores in the center of the dis-tribution (i.e., Japan and Nepal in the forties and South Africa and Ireland in the sixties).

We used Transparency International's (2002) Corruption Index (Figure 1) in this research. According to Transparency International, the least corrupt country in our sample was rated as a 9.0 and the most corrupt country as a 2.2, which is the opposite of what one would expect. To make the results of our analysis more interpretable to readers, we subtracted Transparency International's scores from ten (i.e., higher scores now represent the more corrupt countries). Our transformation (Figure 1) results in a score of 7.8 for Ecuador (i.e., the most corrupt country in our sample) and 1.0 for Canada (i.e., the least corrupt country in our sample). While the spread for the translated corruption scores is not as diverse as the Individualism scores, the scores still are representative of most of the countries except those with the worst problem with corruption. 
FIGURE 1: Hofstede's Individualism and Transparency International's Corruption Indices

Individualism
\begin{tabular}{|l|l|l|l|l|l|l|l|l|l|} 
EC & CO & HK & & NE & SP & IR & CA & \\
\hline $01-10$ & $11-20$ & $21-30$ & $31-40$ & $41-50$ & $51-60$ & $61-70$ & $71-80$ & $81-90$ & $91-100$
\end{tabular}

Corruption

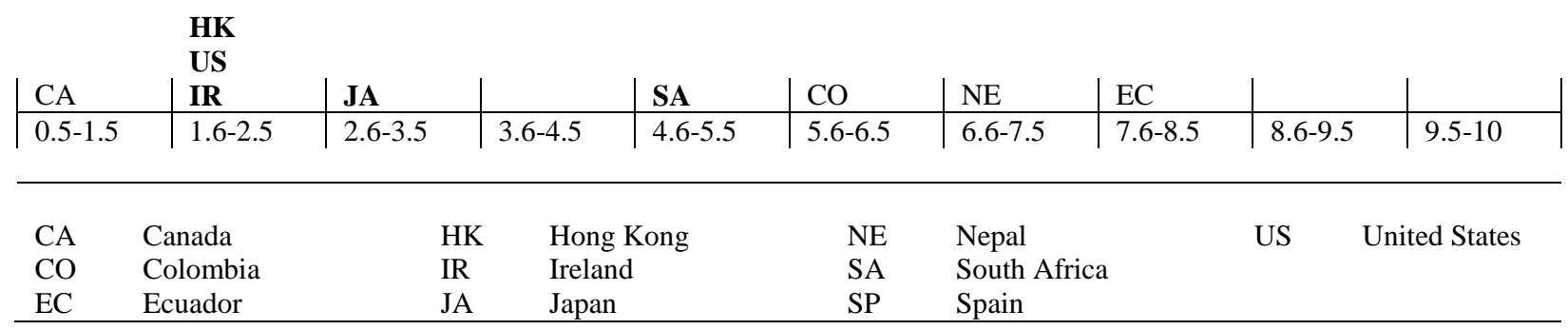

\subsection{Research Instrument}

Our research instrument consisted of five questions, the Impression Management questionnaire (Paulus 1986), and a short background data questionnaire. The instrument was purposely kept short so that the probability of students randomly responding to the questionnaire was minimized. We also included a background questionnaire that asked the participants to provide their home country, gender, and major. Question 1 dealt with bribing a police officer and was adapted from Stevens et al. (1993). The remaining four questions in our survey were taken and modified from Duizend and McCann's (1998) study concerning corruption (see Appendix A). For five of the ten countries (Colombia, Ecuador, Japan, Nepal, and Spain), a person translated the survey into a country's language; then, the survey was back-translated by a second person. The dollar amounts in Questions 1 and 4 were converted into the local currency. The surveys were given to the contact person who was usually a professor teaching at a university in the country. The contact person distributed the surveys to business students and returned the completed surveys.

TABLE 2: Mean Responses by Country and Gender

\begin{tabular}{|c|c|c|c|c|c|c|c|c|c|c|c|c|}
\hline \multirow{2}{*}{$\begin{array}{l}\text { Question } \\
\text { Country/Gender }\end{array}$} & \multicolumn{2}{|c|}{ One } & \multicolumn{2}{|c|}{ Two } & \multicolumn{2}{|c|}{ Three } & \multicolumn{2}{|c|}{ Four } & \multicolumn{2}{|c|}{ Five } & \multicolumn{2}{|c|}{ IMS } \\
\hline & $\mathbf{M}$ & $\mathbf{W}$ & $\overline{\mathbf{M}}$ & $\mathbf{W}$ & $\bar{M}$ & $\mathbf{W}$ & $\mathbf{M}$ & $\mathbf{W}$ & $\mathbf{M}$ & $\mathbf{W}$ & $\mathbf{M}$ & $\mathbf{W}$ \\
\hline Canada & 2.7 & 1.7 & 1.2 & 1.2 & 1.5 & 1.4 & 1.6 & 1.5 & 3.2 & 2.8 & 5.1 & 6.3 \\
\hline Colombia & 2.2 & 1.8 & 1.0 & 1.3 & 1.3 & 1.4 & 1.6 & 1.6 & 2.7 & 2.3 & 7.1 & 7.6 \\
\hline Ecuador & 1.9 & 1.7 & 1.3 & 1.1 & 1.5 & 1.2 & 1.5 & 1.2 & 2.3 & 2.4 & 5.7 & 7.8 \\
\hline Hong Kong & 1.2 & 1.3 & 1.4 & 1.2 & 1.6 & 1.9 & 1.2 & 1.3 & 2.6 & 2.8 & 5.3 & 6.2 \\
\hline Ireland & 2.1 & 1.9 & 1.3 & 1.2 & 1.7 & 1.6 & 1.8 & 1.7 & 3.9 & 3.0 & 5.0 & 5.8 \\
\hline Japan & 1.5 & na & 1.3 & na & 1.5 & na & 1.6 & na & 1.5 & na & 6.1 & na \\
\hline Nepal & na & 2.2 & na & 1.1 & na & 1.9 & na & 2.2 & na & 2.5 & na & 6.4 \\
\hline South Africa & 2.8 & 2.0 & 1.3 & 1.1 & 1.4 & 1.2 & 1.6 & 1.1 & 2.9 & 2.6 & 5.2 & 7.3 \\
\hline Spain & 1.4 & 1.1 & 1.1 & 1.0 & 1.4 & 1.2 & 2.4 & 1.5 & 3.6 & 3.2 & 5.4 & 7.3 \\
\hline United States & 2.8 & 2.7 & 1.9 & 1.7 & 2.2 & 2.1 & 2.5 & 2.2 & 3.4 & 3.4 & 4.3 & 4.9 \\
\hline Country Avg & 2.1 & 1.9 & 1.4 & 1.3 & 1.6 & 1.6 & 1.8 & 1.7 & 3.0 & 2.8 & 5.4 & 6.5 \\
\hline IMS & & & & & Ie $\mathrm{s}$ & $\mathrm{e}(\mathrm{Pc}$ & 198 & & & & & \\
\hline Shaded Areas & & & & & sed & he & & & & & & \\
\hline
\end{tabular}


Hofstede $(1991,112)$ maintains that culture is a system of shared values and beliefs that represent a "set of likely reactions of citizens with a common mental programming. [These] reactions need not be found within the same persons, but only statistically more often in the same society." Hofstede used the mean response for each country's sample as his construct. Because Hofstede's constructs represent the average reaction of individuals from each country, our participants' responses and IMS scores were averaged to produce an estimate by country and gender. This procedure produced 18 unique estimates for each question (i.e., two for each country minus the sample of female students from Japan and male students from Nepal) that we used as our dependent variables. Table 2 shows the means of the data for all ten countries. As part of our questionnaire, we also used the Impression Management Subscale (IMS) of Paulhus' (1986) Balanced Inventory of Desirable Responding (BIDR, see Appendix B). The impression management portion of the BIDR is a 20-item subscale that had the overall highest correlation with seven other social desirability measures reported by Randall and Fernandes (1991).

\subsection{Results}

\subsection{Hypotheses Dealing with Bribes}

For the purposes of the analysis, we reordered the research questions. The findings for the questions dealing with bribes are shown in Table 3. For Question One, the data indicate that, as Individualism and Corruption increase, the average response tends to move towards the rating of "more acceptable". We received anecdotal evidence that supports our finding on social desirability response bias. The individual who collected our data in Ecuador noted that the class instructor commented "we all know that we bribe the police to avoid speeding tickets and yet everyone says that it is unacceptable to bribe a police officer". Finally, the model also indicates that, as scores on the Impression Management Subscale increase, subjects rated the action ass "less acceptable" (i.e., more socially desirable).

TABLE 3: Stepwise Regression Models for Questions Dealing with Bribes

Question 1: Offering a bribe to a police officer.

$\begin{array}{lllll}\frac{\text { Model }}{\text { Regression }} & \frac{\text { Adj Rsquare }}{0.609} & \frac{\text { DF }}{14} & \frac{\text { F Factor }}{9.84} & \frac{\text { Significance }}{0.0010} \\ \text { Term } & \underline{\text { Coefficient }} & \underline{\text { Std Error }} & \underline{\text { T Stat }} & \underline{\text { P-value }} \\ \text { Intercept } & 1.91 & 0.72 & 4.07 & 0.0192 \\ \text { Corruption } & 0.19 & 0.05 & 3.59 & 0.0011 \\ \text { Individualism } & 0.01 & 0.00 & -2.31 & 0.0030 \\ \text { IMS } & -0.24 & 0.10 & & 0.0367\end{array}$

Question 4: President bribes board members to keep silent.

$\begin{array}{lllll}\frac{\text { Model }}{\text { Regression }} & \frac{\text { Adj Rsquare }}{0.285} & \frac{\text { DF }}{16} & \frac{\text { F Factor }}{7.78} & \frac{\text { Significance }}{0.0132} \\ \text { Term } & \underline{\text { Coefficient }} & \underline{\text { Std Error }} & \underline{\text { T Stat }} & \underline{\text { P-value }} \\ \text { Intercept } & 3.05 & 0.50 & -2.79 & 0.0001 \\ \text { IMS } & -0.23 & 0.08 & 0.0132\end{array}$

\begin{tabular}{ll}
\hline Individualism & One of Hofstede's (1981) cultural constructs. \\
Corruption & Transparency International's index subtracted from 10. \\
IMS & The Impression Management Subscale score (Paulhus, 1986) \\
\hline
\end{tabular}

Table 3 also shows the model for the question involving the president of a company bribing members of the board of directors to ensure their silence. The data for this model indicate that the Impression Management Subscale 
was the only significant variable. As scores on this measure increase, subjects rated the action as "less acceptable" (i.e., more socially desirable).

\subsection{Hypotheses Dealing with Other Ethical Issues}

Table 4 shows the results of the questions dealing with selling a defective product, overstating the costs of repairs, and using company money for a personal vacation. In two of these scenarios, we found that scores on the IMS were significant. Except for the case involving a personal vacation, as the IMS scores increased, subjects believed the action was "less ethical" (i.e., a negative coefficient). After controlling for IMS, gender was significant in the model for overstating the cost of repairs on automobiles - male students thought it was more unacceptable. Finally, in the personal vacation model, individuals from more Individualistic countries perceived the action as being more ethical.

TABLE 4: Stepwise Regression Models for Questions Dealing with Other Issues

Question 2: Selling a product with a defect.

$\begin{array}{lllll}\frac{\text { Model }}{\text { Regression }} & \frac{\text { Adj Rsquare }}{0.407} & \frac{\text { DF }}{16} & \frac{\text { F Factor }}{12.69} & \underline{\text { Significance }} \\ \text { Term } & \underline{\text { Coefficient }} & \underline{\text { Std Error }} & \underline{\text { T Stat }} & \underline{8.0026} \\ \text { Intercept } & 2.12 & 0.25 & -3.56 & 0.0001 \\ \text { IMS } & -0.14 & 0.04 & 0.0026\end{array}$

Question 3: Overstating cost of repairs.

$\begin{array}{lllll}\text { Model } & \frac{\text { Adj Rsquare }}{0.607} & \underline{\text { DF }} & \underline{\text { F Factor }} & \underline{14.11} \\ \text { Regression } & \underline{\text { Coefficient }} & \underline{\text { Std Error }} & \underline{\text { T Stat }} & \underline{0.0004} \\ \text { Term } & 3.34 & 0.34 & \underline{\text { P-value }} \\ \text { Intercept } & -0.29 & 0.07 & -5.30 & 0.0001 \\ \text { IMS } & -0.14 & 0.06 & -2.73 & 0.0001 \\ \text { Gender } & & & & 0.0155\end{array}$

Question 5: Using company money for personal vacation.

$\begin{array}{lllll}\frac{\text { Model }}{\text { Regression }} & \frac{\text { Adj Rsquare }}{0.344} & \frac{\text { DF }}{16} & \underline{\text { F Factor }} & \frac{\text { Significance }}{0.41} \\ \frac{\text { Term }}{\text { Intercept }} & \underline{\text { Coefficient }} & \underline{\text { Std Error }} & \underline{\text { T Stat }} & \underline{\text { P-value }} \\ \text { Individualism } & 2.27 & 0.23 & 2.96 & 0.0001 \\ \end{array}$

\begin{tabular}{|c|c|}
\hline Individualism & One of Hofstede's (1981) cultural constructs. \\
\hline IMS & The Impression Management Subscale score (Paulhus, 1986) \\
\hline Gender & Male Students (1) $\quad$ Female Students (0) \\
\hline
\end{tabular}

\subsection{Additional Analyses}

To avoid speculation that either the use of India's cultural constructs for Nepal or that the smaller samples for Ecuador and Nepal were essential to the analysis, we analyzed the data without the male students from Ecuador and the female students from Nepal (i.e., those with samples of less than 30 participants). Our analyses indicate that the models remained stable even after removing the data points for samples that had less than 30 participants. The explanatory power (i.e., adjusted $\mathrm{r}^{2}$ ) for all five of the models was also relatively stable: bribing police officer .61 
(original) versus .64 (revised); bribing board members .29 versus .39; selling defective product .41 versus .40 ; overstating repair costs .61 versus .69; and personal vacation .34 versus .26 .

\subsection{Conclusions}

The most important finding of this research is the consistent significance of social desirability response bias in responses to ethical dilemmas. This finding supports the concern of Randall and Gibson (1990) who note that, even though self-reported data were used in 90 percent of business ethics research since 1960, only one out of 96 articles considered social desirability response bias as part of their research design. Our data suggest that social desirability response bias should be controlled for in ethics research, cross-cultural research, and any research involving self-reported data.

We found that the acceptability of unethical issues increased as a country's Individualism increased for the cases involving bribing a police officer and billing a vacation for one's spouse as a business expense. This finding supports the results of Arnold et al. (1999) and suggests that future international research should include Hofstede's (1980) cultural constructs as independent variables. Our findings suggest that, while individuals report bribery as being unethical, conclusions drawn from these responses should be adjusted for the level of social desirability response bias of different cultures.

While there was a positive association between bribery and corruption in the first question (Table 3), there was not a significant association with the general dishonest practices in the remaining four questions. However, we cannot become too confident this finding because corruption bordered on significance in each of these scenarios. Perhaps these practices are universally accepted or rejected, which suggests that further research is needed using variables that were not considered in this research.

This study has at least three limitations. First, ten countries is not a large enough sample to generalize our conclusions with certainty. Indeed, it is possible for a group of countries to "share common ethical behavior with respect to a given situation, even though a global consensus does not exist" (Buller et al. 1991, 769). Second, only business majors were surveyed; it cannot be said that corporate managers would have similar responses. Third, we only examined five ethical situations. To resolve these limitations, we suggest that this study be continued using additional countries, majors, and scenarios.

\section{References}

1. Adams, Janet S., Armen Tashchian, and Ted H. Shore, "Frequency, Recall, and the Usefulness of Undergraduate Ethics Education," Teaching Business Ethics, Vol. 3 (3), pp. 241-253, 1999.

2. Argandona, Antonio, "Business Ethics in Spain," Journal of Business Ethics, Vol. 22 (3), pp. 155-173, 1999.

3. Arnold, Donald F., Sr., Richard A. Bernardi, and Presha E. Neidermeyer, "Reply to Comments on: An Investigation of the Effect of 'Auditor Involvement' on Issues of Independence in Europe," Auditing: A Journal of Practice \& Theory, Vol. 18 (Supplement), pp. 79-83, 1999.

4. Arruda, M Cecilia, "Business Ethics in Latin America," Journal of Business Ethics, Vol. 16 (14), pp. 15971603, 1997.

5. Bernardi, Richard A., and Donald F. Arnold, Sr., "An Examination of Moral Development within Public Accounting by Gender, Staff Level, and Firm," Contemporary Accounting Research, Vol. 14 (4), pp. 653668, 1997.

6. Beltramini, Richard F., Robert A. Peterson, and George Kozmetsky, "Concerns of College Students Regarding Business Ethics,” Journal of Business Ethics, Vol. 3 (3), pp. 195-200, 1984.

7. Buller, Paul F., John J. Kohls, and Kenneth S. Anderson, "The Challenge of Global Ethics," Journal of Business Ethics, Vol. 10 (10), pp. 767-775, 1991.

8. Chakraborty, S. K., "Business Ethics in India," Journal of Business Ethics, Vol. 16 (14), pp. 1529-1538, 1997. 
9. Cote, Jane M., and Debra L. Sanders, "Herding Behavior: Explanations and Implications," Behavioral Research in Accounting, Vol. 9, pp. 20-45, 1997.

10. Duizend, Johnny, and Greg K. McCann, "Do Collegiate Business Students Show a Propensity to Engage in Illegal Business Practices?” Journal of Business Ethics, Vol. 17 (3), pp. 229-238, 1998.

11. Dunfee, Thomas W., and Patricia Werhane, "Report on Business Ethics in North America," Journal of Business Ethics, Vol. 16 (14), pp. 1589-1595, 1997.

12. Enderle, Georges, “A Worldwide Survey of Business Ethics in the 1990s," Journal of Business Ethics, Vol. 16 (14), pp. 1475-1483, 1997.

13. Enderle, Georges, "A Comparison of Business Ethics in North America and Continental Europe," Business Ethics: A European Review, Vol. 5 (1), pp. 33-46, 1996.

14. Ganster, Daniel C., Harry W. Hennessey, and Fred Luthans, "Social Desirability Response Effects: Three Alternative Models," Academy of Management Journal, Vol. 26 (2), pp. 321-331, 1983.

15. Gendall, Philip, and Janet Hoek, "Estimating a Socially Undesirable Behavior," Marketing Bulletin, Vol. 3, pp. $1-8,1982$.

16. Hofstede, Geert, Cultures and Organizations: Software of the Mind, McGraw Hill, New York, 1991.

17. Hofstede, Geert, Culture Dimensions in Management and Planning. Asia Pacific Journal of Management, Vol. 1 (2), pp. 81-99, 1984.

18. Hofstede, Geert, Culture's Consequences: Comparing Values, Behaviors, Institutions, and Organizations Across Nations, Sage Publications, Beverly Hills, California, 1980.

19. Karnes, Allan, Julie Sterner, Robert Welker, and Frederick Wu, "A Bicultural Study of Independent Auditors - Perceptions of Unethical Business Practices," International Journal of Accounting, 24 (1), pp. 29-41, 1989.

20. Kalton, Graham, and Howard Schuman, "The Effect of the Question on Survey Responses: A Review," Journal of the Royal Statistical Society, Vol. 145 (1), pp. 42-57, 1982.

21. Kohlberg, Lawrence, "Stages and Sequences: the Cognitive Developmental Approach to Socialization," in M. Hoffman (Ed.), Handbook of Socialization Theory and Research, Rand McNally, Chicago, IL, 1969.

22. Merritt, Ashleigh, "Culture in the Cockpit: Do Hofstede's Dimensions Replicate?" Journal of CrossCultural Psychology, Vol. 31 (3), pp. 283-301, 2000.

23. Paulhus, Delroy L., "Self-Deception and Impression Management in Test Responses," pp. 17-41, in A. Angleiter and J. S. Wiggins (Eds.), Personality Assessment via Questionnaire: Current Issues in Theory and Measurement, Springer-Verlag, Berlin, Germany, 1986.

24. Peterson, Robert A., Richard F. Beltramini, and George Kozmetsky, "Concerns of College Students Regarding Business Ethics: A Replication,” Journal of Business Ethics, Vol. 10 (10), pp. 733-738, 1991.

25. Randall, Donna M., and Annetta M. Gibson, "Methodology in Business Ethics Research: A Review and Critical Assessment," Journal of Business Ethics, Vol. 9 (6), pp. 457-472, 1990.

26. Randall, Donna M., and Maria F. Fernandes, "The Social Desirability Response Bias in Ethics Research," Journal of Business Ethics, Vol. 10 (11), pp. 805-817, 1991.

27. Rest, James R., Development in Judging Moral Issues, With a Foreword by Lawrence Kohlberg. University of Minnesota Press, Minneapolis, MN, 1979a.

28. Rest, James R., Defining Issues Test, Center for the Study of Ethical Development, University of Minnesota Press, Minneapolis, MN, 1979b.

29. Robertson D. H., and E. Anderson, "Control System and Task Environment Effects on Ethical Judgment: An Exploratory Study of Industrial Salespeople," Organizational Science, Vol. 4 (November), pp. 617-644, 1993.

30. Rossouw, Gedeon J. "Business Ethics in South Africa," Journal of Business Ethics, Vol. 16 (14), pp. 15391547, 1997.

31. Smith, Aileen, "Testing the Stability of the Global Concept of Culture in an Accounting Context," Accounting Enquiries, Vol. 11 (2), pp. 227-248, 2002.

32. Stevens, Robert E., O. Jeff Harris, and Stan Williamson, "A Comparison of Ethical Evaluations of Business School Faculty and Students: A Pilot Study," Journal of Business Ethics, Vol. 12 (8), pp. 611-619, 1993.

33. Swamy, Anand, Stephen Knack, Young Lee, and Omar Azfar, "Gender and Corruption," Journal of Development Economics, Vol. 64 (1), pp. 25-55, 2001. 
34. Taka, Iwao, "Business Ethics in Latin America," Journal of Business Ethics, Vol. 16 (14), pp. 1597-1603, 1997.

35. Transparency International, "Bribe Payers Index," http://www.trasparency.org/cpi/2002/cpi2002.en.html, 2002.

36. Transparency International, "Corruption Perceptions Index: An Index of Perceptions of Business People of Corruption around the World," http://www.trasparency.org/cpi/2002/ cpi2002.en.html, 2002.

37. Triandis, Harry C., "A Theoretical Framework for the More Efficient Construction of Culture Assimilators," International Journal of Intercultural Relations, Vol. 8 (3), pp. 301-330, 1984.

38. Triandis, Harry C., Richard Brislin, and C. Harry Hui, "Cross-Cultural Training across the IndividualismCollectivism Divide," International Journal of Intercultural Relations, Vol. 12 (3), pp. 269-289, 1988.

39. Van Luijk, Henk J. L., "Business Ethics in Western and Northern Europe: A Search for Effective Alliances,” Journal of Business Ethics, Vol. 16 (14), pp. 1579-1587, 1997.

40. Wingate, Michelle L., "An Examination of Cultural Influence on Audit Environment." Research in Accounting Regulation, Vol. 11 (Supplement), pp 115-127, 1997.

41. Zerbe, Wilfred J., and Delroy L. Paulhus, "Socially Desirable Responding in Organizational Behavior: A Reconception," Academy of Management Review, Vol. 12 (2), pp. 250-264, 1987.

\section{Endnotes}

Only four of the ten countries in our sample are in part of data set for Transparency International's (2002) Bribery Index.

In each country, there were international students who responded to the survey; these students were eliminated from our sample.

The missing cultural areas in our sample are Near Eastern, Germanic, and Nordic.

Differences in sample size should be compensated for by the averaging process in our analysis.

\section{Appendix A: Ethics Questionnaire}

Using the scale below as a guide, write a number beside each statement to indicate how much you agree with it.

\begin{tabular}{l|l|l|l|l|l|l}
1 & 2 & 3 & 4 & 5 & 6 & 7 \\
\hline Totally & & & No & & & Totally \\
Unacceptable & & Opinion & & & Acceptable
\end{tabular}

1. A police officer pulls over a speeding vehicle and the person in the vehicle proceeds to hand him a fifty dollar bill, so he will not give him a ticket. The police officer takes the money and allows the vehicle to go.

2. A manufacturer knowingly sells a product with a material defect that could cause injury to consumers.

3. A repair shop overstates the extent of repairs that must be done on customers' automobiles and charges them for work that was not done.

4. A president of a company gives each of its board members $\mathbf{\$ 1 0 , 0 0 0}$ to keep them quiet about the company performing illegal actions.

5. A business executive takes his/her spouse on an international trip and charges the cost of both their trips as a business expense.

Note: Dollar amounts in cases one and four were converted into the local currency. 


\section{Appendix B: Image Management Subscale}

Using the scale below as a guide, write a number beside each statement to indicate how much you agree with it.

\begin{tabular}{l|l|l|l|l|l|l}
$\mathbf{1}$ & $\mathbf{2}$ & $\mathbf{3}$ & $\mathbf{4}$ & $\mathbf{5}$ & $\mathbf{6}$ & $\mathbf{7}$ \\
\hline Not True & & & Somewhat true & & & Very true
\end{tabular}

1. Sometimes I tell lies if I have to.

2. I never cover up my mistakes.

3. There have been occasions when I have taken advantage of someone.

4. I never swear.

5. I sometimes try to get even rather that forgive and forget.

6. I always obey laws, even if I'm unlikely to get caught.

7. I have said something bad about a friend behind his/her back.

8. When I hear people talking privately, I avoid listening.

9. I have received too much change from a salesperson without telling him or her.

10. I always declare everything at customs.

11. When I was young, I sometimes stole things.

12. I have never dropped litter on the street.

13. I sometimes drive faster than the speed limit.

14. I never read sexy books or magazines.

15. I have done things that I don't tell other people about.

16. I never take things that don't belong to me.

17. I have taken sick leave from work or school even though I wasn't really sick.

18. I have never damaged a library book or store merchandise without reporting it.

19. I have some pretty awful habits.

20. I don't gossip about other people's business. 
Notes 